\title{
UNSUCCESSFUL DELIVERY OF TETRANDRINE FROM COLON-TARGETED DOSAGE FORMS COMPRISING ALGINATE/HYDROXYPROPYL METHYLCELLULOSE AND ALGINATE-CHITOSAN BEADS
}

\author{
RADITYA ISWANDANA*, METAH PUTRI MUTIA, FARAHIA KHAIRINA WIDYANINGRUM
}

Laboratory of Pharmaceutics and Pharmaceutical Technology, Faculty of Pharmacy, Universitas Indonesia, Depok 16424, Indonesia. Email: raditya@farmasi.ui.ac.id

Received: 15 June 2018, Revised and Accepted: 20 November 2018

\section{ABSTRACT}

Objective: The objective of this study was to optimize the formulations of antifibrotic tetrandrine beads using alginate and various concentrations of hydroxypropyl methylcellulose (HPMC) and chitosan.

Methods: Beads were formulated with six (F1-F6) concentrations of polymer and were then characterized using scanning electron microscopy, differential scanning calorimetry, and X-ray diffraction; these beads were used for measurements of moisture contents, swelling, and in vitro drug release.

Results: Beads with the highest concentrations of HPMC and chitosan produced the highest entrapment efficiencies of $49.83 \%$ and $50.71 \%$, respectively. Moreover, drug release under stomach conditions ( $\mathrm{HCl} \mathrm{pH} 1.2$ medium) was restricted to $75.01 \%, 61.01 \%, 51.86 \%, 74.84 \%, 66.00 \%$, and $41.63 \%$ with increasing HPMC and chitosan concentrations (F1-F6, respectively).

Conclusion: Beads of all formulations showed inadequate retention of tetrandrine under pH conditions of the upper gastrointestinal tract and would likely be unsuccessful as colon-targeted dosage forms.

Keywords: Alginate, Antifibrotic tetrandrine beads, Chitosan, Hydroxypropyl methylcellulose, Ionic gelation.

(C) 2018 The Authors. Published by Innovare Academic Sciences Pvt Ltd. This is an open access article under the CC BY license (http://creativecommons. org/licenses/by/4. 0/) DOI: http://dx.doi.org/10.22159/ijap.2018.v10s1.88

\section{INTRODUCTION}

Colon-targeted drug delivery was previously used to advance therapy for localized disease and to minimize the side effects of drugs in the gastrointestinal tract [1]. These systems were designed to reach the colon with minimal release of enzyme- and pH-sensitive drugs in the upper gastrointestinal tract [2]. Specifically, these drug delivery systems should achieve long retention times [3], robustness to unique $\mathrm{pH}$ conditions [4], decreased doses and side effects, and increase bioavailability, especially for drugs with low absorption [5].

$\mathrm{pH}$-sensitive mechanisms are critical to drug delivery systems for the gastrointestinal tract because $\mathrm{pH}$ conditions vary from highly acidic to almost neutral in the colon [4]. Beads are multiparticulate systems that have been considered as pharmaceutical dosage forms for colon-targeted drug delivery [6] and may be used to control and extend drug release [2]. These beads are formed using ionic gelation methods to produce cross-linked complexes of polyelectrolyte polymers. Tetrandrine is an antifibrotic agent for the treatment of intestinal fibrosis, which is characterized by excessive deposition of the extracellular matrix under conditions of ulcerative colitis and Crohn's disease [7]. Intestinal fbrosis is caused by an excess deposition of the extracellular matrix resulting from chronic inflammation and impaired wound healing in the intestine [8]. In addition, patients with fibrosis who were not effectively treated with systemic immunosuppressants benefited from drugs with localized effects [9], and in another study, antifibrotic site-directed effects of tetrandrine were achieved by targeting to the colon [10].

Polymers with crosslinking capacity, such as alginate, may facilitate tetrandrine delivery to the colon by beads because of the resulting crosslinked complexes form three-dimensional networks that can be used to entrap bioactive substances or drugs [11]. Alginate forms biodegradable polymers in which the stability of dosage forms can be manipulated and drug release can be controlled according to $\mathrm{pH}$ sensitivity, offering the potential for colon-targeted drug delivery [12,13]. However, alginate has a low drug entrapment efficiency, necessitating the use of combination polymers with polymer agents, such as hydroxypropyl methylcellulose polymer (HPMC) and chitosan, which improve drug entrapment and release profiles [14].

HPMC was chosen due to its stability in the gastrointestinal tract, where $\mathrm{pH}$ conditions widely vary. $\mathrm{HPMC}$ limits drug release at $\mathrm{pH} 3-11[15,16]$. HPMC also establishes semi-interpenetrating networks (semi-IPNs) with alginate, leading to the formation of beads when the mixture is dropped into calcium chloride solution. Herein, we performed experiments with chitosan based on a previous study, showing that it can facilitate targeting to the colon [14]. Like HPMC, chitosan is a polysaccharide that forms polymers that are biodegradable by colonic microflora. Specifically, chitosan formed polyelectrolyte cross-linked networks with alginate, and the ensuing electrostatic interactions strengthened the bioadhesive characteristics of alginate and facilitated drug release [5]. Based on these studies, we formulated tetrandrineloaded beads from alginate/HPMC and calcium alginate-chitosan and compared colon targeting using six formulations of each with varying polymer concentrations.

\section{MATERIALS AND METHODS}

Tetrandrine (Shaanxi Ciyuan Biotech, China), tetrandrine standard (Sigma Aldrich, Singapore), sodium alginate (Shandong Jiejing Group Co., China), calcium chloride (Merck, Germany), HPMC (Wuhan Senwayer Century Chemical Co., Ltd., China), chitosan (Bio Chitosan, Indonesia), chloride acid (Brataco, Indonesia), potassium phosphate monobasic (Merck, Germany), sodium hydroxide (Brataco, Indonesia), ethanol (Brataco, Indonesia), Tween 80 (Brataco, Indonesia), and 
deionized water (Brataco, Indonesia) were purchased from their respective suppliers.

\section{Preparation of calcium alginate/HPMC beads}

Sodium alginate and HPMC were separately dissolved in demineralized water, were mixed and homogenized, and were then slowly cooled to room temperature. Tetrandrine was then dissolved in $0.1 \mathrm{~N} \mathrm{HCl}$ and was added to the alginate/HPMC solution and stirred until homogeneous. Subsequently, the blended solution was extruded into $2 \%$ calcium chloride solution using $21 \mathrm{G}$ syringe needle with stirring at $200 \mathrm{rpm}$ $\left(37^{\circ} \mathrm{C}\right)$ for $15 \mathrm{~min}$. Beads were then washed with deionized water and dried at room temperature (Table 1 ).

\section{Preparation of calcium alginate-chitosan beads}

Sodium alginate was dissolved in demineralized water and tetrandrine was dissolved in $0.1 \mathrm{~N} \mathrm{HCl}$, and the two solutions were then homogeneously mixed. Calcium chloride was dissolved in demineralized water, and chitosan was dissolved separately in $1 \%$ glacial acetic acid and was mixed with $1 \mathrm{~N} \mathrm{NaOH}$ to adjust the $\mathrm{pH}$ to about 4.5. The alginate-tetrandrine solution was then extruded into $2 \%$ calcium chloride solution using a 26G syringe needle with stirring at $200 \mathrm{rpm}\left(37^{\circ} \mathrm{C}\right)$ for $15 \mathrm{~min}$. The resulting beads were finally washed with deionized water and dried at room temperature.

\section{Morphological characterization}

Shapes, odors, surface textures, and colors of beads were visually determined.

\section{Scanning electron microscopy}

Shapes and morphologies of beads were observed using a scanning electron microscope (SEM; Hitachi SU-3500, Japan) after placing the beads in the sample holder and applying a vacuum [14].

\section{Particle size distributions}

The diameters of 300 beads were measured using calipers with $0.02 \mathrm{~mm}$ accuracy, and the mean particle sizes and size distributions were calculated [17].

\section{Determination of moisture contents}

Moisture contents were measured using a moisture balance (Adam, USA). Briefly, bead samples of about $1 \mathrm{~g}$ were placed in an aluminum pan, and percentage water contents were determined when no further weight changes were observed.

\section{Process efficiency}

To calculate recovery values, we compared the weights of all materials used during the production of beads with the weights of the resulting beads using the following formula:

Process Efficiency $(\%)=\frac{\text { Weight of the dried beads }(\text { gram })}{\text { Total weight of material used }(\text { gram })} \times 100 \%$

\section{Determinations of entrapment efficiencies and drug contents}

Entrapment efficiency was measured after extracting tetrandrine from beads. To this end, beads were soaked in buffer phosphate-buffered saline (PBS) at pH 6.8 for $24 \mathrm{~h}$ and were stirred at $100 \mathrm{rpm}$ until they disintegrated. $\mathrm{HCl}(\mathrm{pH} 1.2)$ was then added to a volume of $50 \mathrm{ml}$, and solutions were finally centrifuged at $2500 \mathrm{rpm}$ for $15 \mathrm{~min}$. Supernatants were then collected and diluted again to $50 \mathrm{ml}$ in $\mathrm{HCl}(\mathrm{pH} \mathrm{1.2)}$, and tetrandrine contents were determined using a ultraviolet-visible (UV-Vis) spectrophotometer (Shimadzu UV-1800, Japan) at $280 \mathrm{~nm}$. Entrapment efficiencies and drug contents were calculated using the following formulas [18]:

Entrapment efficiency $(\%)=\frac{\text { Practical drug loading }(\mathrm{mg})}{\text { Theoritical drug loading }(\mathrm{mg})} \times 100 \%$

Drug content $(\%)=\frac{\text { Practical drug loading }(\mathrm{mg})}{\text { Amount of beads }(\mathrm{mg})} \times 100 \%$

\section{Differential scanning calorimetry}

Tetrandrine, alginate, HPMC, chitosan, calcium chloride, alginate/HPMC beads, alginate-chitosan beads, tetrandrine-loaded alginate/HPMC beads, and tetrandrine-loaded alginate-chitosan beads were analyzed using a differential scanning calorimeter (DSC; Perkin Elmer DSC8000, USA). In these analyses, $5 \mathrm{mg}$ samples were placed in aluminum cylinders under a flow of nitrogen and were heated at $10^{\circ} \mathrm{C} / \mathrm{min}$ from $30^{\circ} \mathrm{C}$ to $350^{\circ} \mathrm{C}$.

\section{X-ray diffraction}

To determine whether tetrandrine is amorphous or crystalline in alginate/HPMC and alginate-chitosan beads, we recorded diffraction patterns using an X-ray diffractometer with $\mathrm{Cu}$ irradiation at $40 \mathrm{kV}$ and $40 \mathrm{~mA}$.

\section{Swelling index analysis}

Bead formulations ( $1 \mathrm{~g}$ ) were soaked in 25-mL aliquots of PBS ( $\mathrm{pH}$ 6.8) at $37^{\circ} \mathrm{C}$ and were weighed after $5,10,15,30,45$, and $60 \mathrm{~min}$. Swelling indexes were then calculated, as previously described by Pandey et al. [19], using the following formula:

Percentage swelling $(\%)=\frac{W 2-W 1}{W 1} \times 100$

Where $\mathrm{W}_{1}$ is the weight of dried beads and $\mathrm{W}_{2}$ is the weight of swollen beads.

\section{Fourier-transform infrared (FTIR) analyses}

We performed FTIR spectroscopy (Shimadzu FTIR 8400S, Japan) to investigate interactions between the components in prepared formulations [20]. Samples of alginate, HPMC, chitosan, their composite beads, and loaded beads were crushed with dry potassium bromide, and analyses were performed at $400-4000 \mathrm{~cm}^{-1}$.

\section{In vitro drug release studies}

Beads were placed in $0.1 \mathrm{~N} \mathrm{HCl}$ for $2 \mathrm{~h}$, followed by PBS ( $\mathrm{pH} 7.4$ ) for $3 \mathrm{~h}$, and then PBS (pH 6.8) for 2 h. PBS solutions contained Tween 80 (2\%, $\mathrm{v} / \mathrm{v}$ ] [2]. $10-\mathrm{ml}$ aliquots of dissolution fluid were withdrawn at regular intervals and were immediately replaced with the same volume of fresh media. Samples were then analyzed using a UV-Vis spectrophotometer at wavelength maxima for each analyte. Sample contents at $\mathrm{n}$ min were calculated using the following formula:

Table 1: Composition of the calcium alginate/HPMC and calcium alginate-chitosan beads containing tetrandrine

\begin{tabular}{|c|c|c|c|c|c|}
\hline Formula & Alginate $(\%, w / v)$ & Calcium chloride $(\%, w / v)$ & HPMC $(\%, w / v)$ & Chitosan $(\%, w / v)$ & Tetrandrine $(\%, w / v)$ \\
\hline Control & 2 & 2 & - & - & 1 \\
\hline F1 & 2 & 2 & 0.5 & - & 1 \\
\hline $\mathrm{F} 2$ & 2 & 2 & 1 & - & 1 \\
\hline F3 & 2 & 2 & 2 & - & 1 \\
\hline F4 & 2 & 2 & - & 0.25 & 1.25 \\
\hline F5 & 2 & 2 & - & 0.5 & 1.25 \\
\hline F6 & 2 & 2 & - & 0.75 & 1.25 \\
\hline
\end{tabular}

HPMC: Hydroxypropyl methylcellulose 
Table 2: Average diameters, moisture contents, process efficiencies, entrapment efficiencies, and drug contents

\begin{tabular}{llllll}
\hline Formula & $\begin{array}{l}\text { Average } \\
\text { diameter }(\boldsymbol{\mu m})\end{array}$ & $\begin{array}{l}\text { Moisture } \\
\text { content } \pm \text { SD }(\%)(\mathbf{n}=3)\end{array}$ & $\begin{array}{l}\text { Process } \\
\text { efficiency }(\%)\end{array}$ & $\begin{array}{l}\text { Entrapment } \\
\text { efficiency } \pm \text { SD (\%) (n=3) }\end{array}$ & $\begin{array}{l}\text { Drug } \\
\text { content } \pm \text { SD (\%) }(\mathbf{n}=3)\end{array}$ \\
\hline Control & 704.27 & $10.44 \pm 1.02$ & 28.85 & $22.73 \pm 1.42$ & $8.74 \pm 0.55$ \\
F1 & 758.70 & $9.06 \pm 0.52$ & 26.62 & $29.60 \pm 1.61$ & $8.46 \pm 0.46$ \\
F2 & 852.61 & $9.46 \pm 0.22$ & 19.92 & $37.58 \pm 0.11$ & $9.39 \pm 0.03$ \\
F3 & 903.52 & $9.67 \pm 0.06$ & 18.98 & $49.83 \pm 0.46$ & $1.97 \pm 0.09$ \\
F4 & 920.27 & $11.69 \pm 0.78$ & 46.95 & $42.26 \pm 1.62$ & $15.33 \pm 0.54$ \\
F5 & 994.8 & $10.76 \pm 1.15$ & 42.5 & $42.93 \pm 1.29$ & $16.90 \pm 0.10$ \\
F6 & 1054.6 & $9.06 \pm 0.69$ & 51.85 & $50.71 \pm 0.31$ & \\
\hline
\end{tabular}

SD: Standard deviation

$n$ minute $(m g)=\frac{(y n-a) \times f p \times M}{b \times 1000}+\ldots+\frac{(y n-a) \times f p \times S}{b \times 1000}$,

Where $\mathrm{yn}$ is tetrandrine absorption at $\mathrm{n} \min , \mathrm{x}$ is the tetrandrine concentration, $\mathrm{fp}$ is a dissolution factor, $\mathrm{M}$ is the volume of release medium, $\mathrm{S}$ is the sample volume, $\mathrm{A}$ is the intercept coefficient, and $\mathrm{B}$ is the slope.

\section{RESULTS}

\section{Particle size distributions}

Beads sizes were determined for 300 beads from each formula using calipers with $0.02 \mathrm{~mm}$ accuracy. From subsequent calculations of mean sizes, $39 \%$ of control beads were distributed between 589 and $671 \mu \mathrm{m}$, whereas $19 \%$ of F1 beads were $772-809 \mu \mathrm{m}$. F2 bead sizes were distributed in $16 \%$ portions at $802-835 \mu \mathrm{m}$ and $836-869 \mu \mathrm{m}, 15 \%$ of F3 beads were $888-914 \mu \mathrm{m}, 30 \%$ of F4 beads were $1058-1100 \mu \mathrm{m}$, and $20.67 \%$ of F6 beads were $1088-1125 \mu \mathrm{m}$. These particle size distributions (Table 2) showed that increasing polymer concentrations are associated with increased bead sizes. Higher concentrations of chitosan and HPMC polymers also contributed to higher retention of mixtures during the gelation process, likely explaining the production of larger beads.

\section{Moisture content determination}

In evaluations of process efficiency (Table 2), water contents of beads indicated hygroscopic properties, similar to those of calcium chloride. In agreement, HPMC is an ether cellulose that acts as a hydrophilic carrier [21].

\section{Process efficiency}

Process efficiencies of F1, F2, F3, F4, F5, and F6 and control beads were $28.85 \%, 26.62 \%, 19.92 \%, 18.98 \%, 46.95 \%$, and $42.5 \%$ and $51.85 \%$, respectively.

\section{Entrapment efficiency and drug content determinations}

The present formulas varied in their capacities to entrap drug substances (Table 2). In experiments with control beads, complexes were not strong enough and had porous surfaces that allowed drug diffusion during the gelation process. We also found that entrapment efficiency increased with polymer concentrations. Foremost, interactions between alginate carboxyl groups and amine protons of chitosan limited the drug diffusion into the medium during gelation, indicating increased solidity of the polymer layers in beads containing alginate or chitosan [22].

\section{Morphological characterization}

Wet alginate/HPMC beads were spherical and were whitish, whereas alginate-chitosan wet beads were spherical and yellowish. None of the beads had strong odors, although alginate-chitosan beads had a weak acidic odor. On drying, beads turned into a yellowish color due to changes in density (Fig. 1).

\section{SEM analyses}

All formulations were observed to be vaguely spherical at $100 \times$ magnification, and rough, wavy, porous, and creviced surfaces were visible at 500× magnification (Fig. 2).

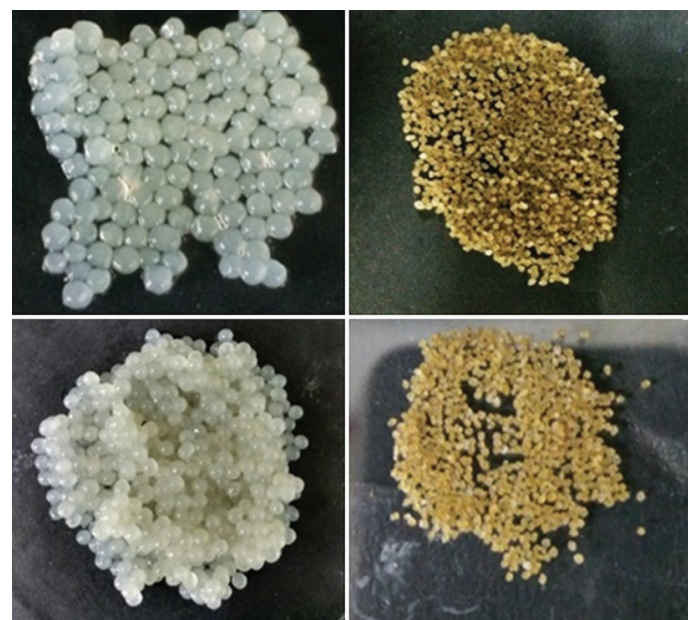

Fig. 1: Beads changed color into a yellowish

\section{DSC analyses}

In thermograms, melting points of the present bead-forming materials differed from those of the formed beads, reflecting chemical interactions between components. In particular, exothermic peaks disappeared in unloaded beads, suggesting that alginate forms a more solid bead structure [23], indicating the establishment of interactions between alginate and HPMC in the formed beads.

Unloaded alginate-chitosan beads showed two endothermic peaks at $75.22^{\circ} \mathrm{C}$ and $205.46^{\circ} \mathrm{C}$, with corresponding melting energies of $142.38 \mathrm{~J} / \mathrm{g}$ and $20.12 \mathrm{~J} / \mathrm{g}$ and an exothermic peak at $274.86^{\circ} \mathrm{C}$ (117.462 J/g). Loaded alginate-chitosan beads had an endothermic peak at $75.71^{\circ} \mathrm{C}(181.52 \mathrm{~J} / \mathrm{g})$ and an exothermic peak at $272.91^{\circ} \mathrm{C}$ $(41.21 \mathrm{~J} / \mathrm{g})$.

\section{X-ray diffraction}

The present diffractograms showed that tetrandrine is in the crystalline phase (Fig. 3), but only small, short, and tight peaks were identified for alginate/HPMC beads. In contrast, alginate-chitosan beads decreased peak heights compared with those of tetrandrine. Some peaks also indicated decreases in drug crystallinity. These data further indicated that tetrandrine was dispersed inside these beads [24] and is compatible with their polymeric matrixes [25]. Peak disappearances in diffractograms indicated the formation of amorphous materials, and differences in peaks reflect the sizes of vestigial tetrandrine crystals [26].

\section{Swelling index}

F1, F2, F3, F4, F5, and F6 formulas swelled by 561.08\%, 1021.36\%, $1116.53 \%, 937.68 \%, 646.3 \%$, and $622.33 \%$, respectively, over $1 \mathrm{~h}$.

\section{FTIR spectroscopy analysis}

FTIR spectra of alginate showed an asymmetric carboxyl group at $1608 \mathrm{~cm}^{-1}$ and a symmetrical carboxyl group at $1429 \mathrm{~cm}^{-1} . \mathrm{G}$ and $\mathrm{M}$ uronic acid were also detected at $1030 \mathrm{~cm}^{-1}$ and $1050 \mathrm{~cm}^{-1}$, respectively. 

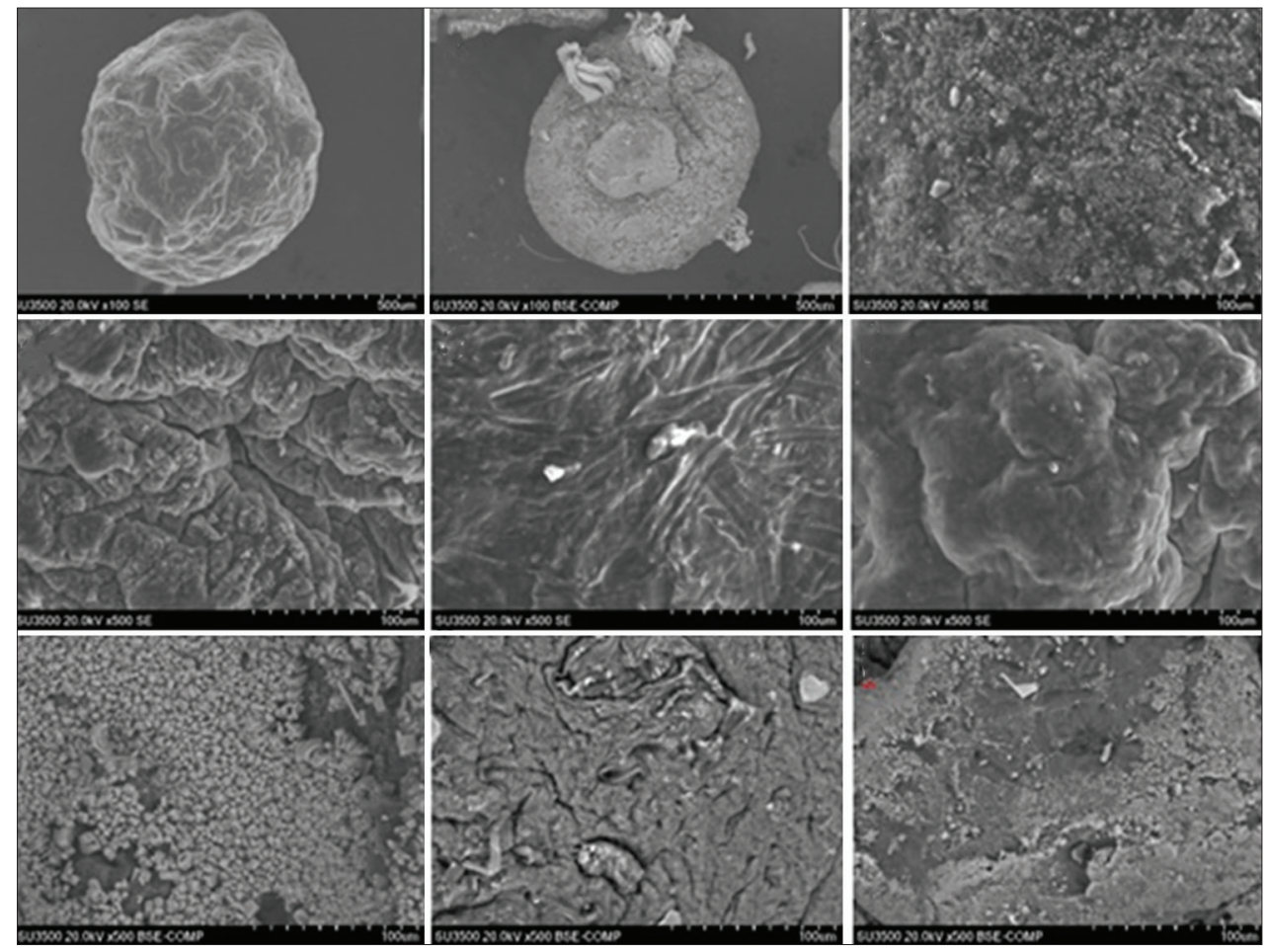

Fig. 2: Scanning electron micrograph under 100x and 500x magnification

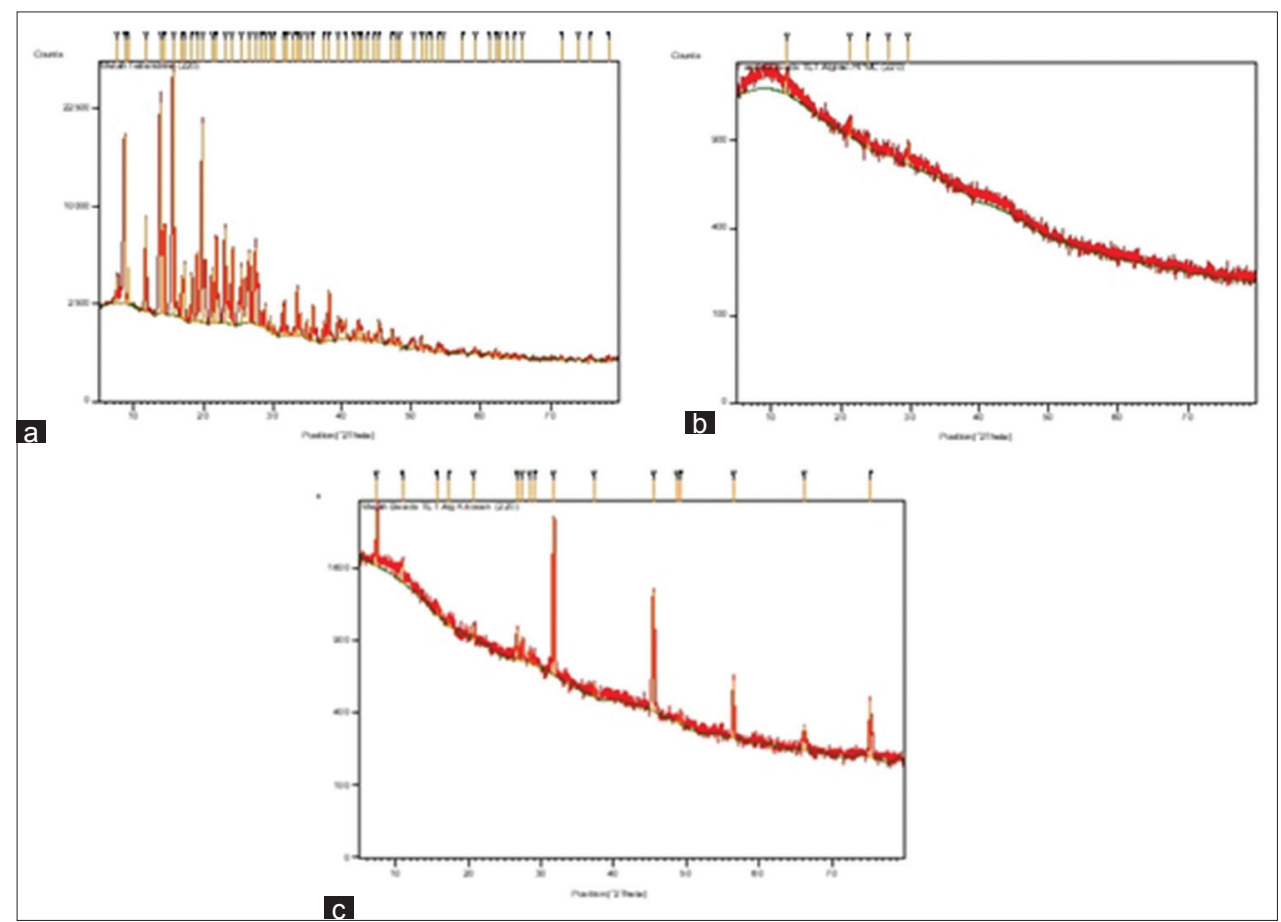

Fig. 3: Diffractograms of (a) tetrandrine (b) tetrandrine loaded alginate/HPMC beads, and (c) tetrandrine loaded alginate-chitosan beads

HPMC in beads had spectra in the range $3500-3400 \mathrm{~cm}^{-1}$, with stretching vibrations of methyl and propyl groups at $2900 \mathrm{~cm}^{-1}$, cyclic groups at $1650-1600 \mathrm{~cm}^{-1}$, broad peaks for cyclic anhydride at $1400-1350 \mathrm{~cm}^{-1}$, and a pyranose ring at 1000-950 $\mathrm{cm}^{-1}$ [12]. Tetrandrine spectra showed the presence of $\mathrm{C}-\mathrm{N}$ groups at $1125 \mathrm{~cm}^{-1}$, the main spectra of benzene at 1455 and $1637 \mathrm{~cm}^{-1}$, and ether spectra at 1025 and $1315 \mathrm{~cm}^{-1}$.

Chitosan showed $\mathrm{N}--\mathrm{H}$ groups at $1655 \mathrm{~cm}^{-1}, \mathrm{C}-\mathrm{N}$ groups at $1315 \mathrm{~cm}^{-1}$, and ether groups at 1151 and $1180 \mathrm{~cm}^{-1}$ (Fig. 4) [14,27].

\section{In vitro release study}

In this study, drug release from beads was shown to be high under acidic conditions ( $\mathrm{HCl}$ at $\mathrm{pH} 1.2)$, which represent the stomach environment, with the release of $>50 \%$ of tetrandrine after $120 \mathrm{~min}$. These observations are consistent with the known acid solubility of tetrandrine [28], but this release may also be affected by the porous and rough surfaces of beads. Hence, under these conditions, semi-IPNs of alginate and HPMC were not strong enough to protect the drugs. Colon-targeted drugs require protection until arrival at the colon, which we modeled using PBS at pH 6.8 (Fig. 5) [29]. 


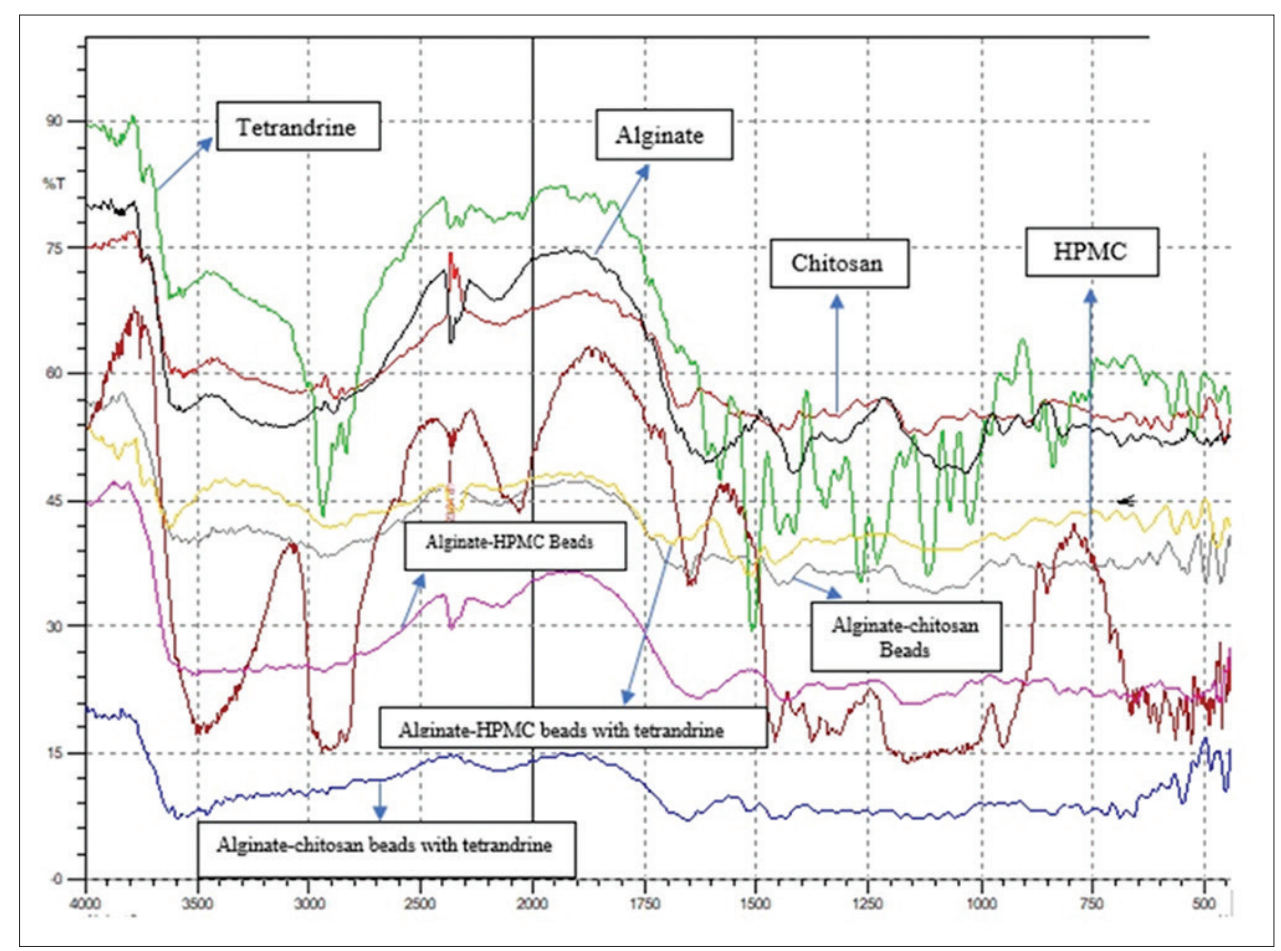

Fig. 4: FTIR spectra



Fig. 5: Cumulative drug release

\section{DISCUSSION}

Alginate beads with lower HPMC concentrations produced wavier surfaces than those with higher concentrations. Rough and porous surfaces were also related to the viscosity of polymer matrix, with lower viscosities decreasing the density of dried beads and causing more wavy surfaces and smaller sizes and shapes [30]. Alginate-chitosan beads had more varying shapes than control beads, reflecting interactions between alginate and chitosan and production of more solid structures. Surface wrinkles were also fewer than on control beads, and a solid structure followed the formation of electrostatic interactions between alginate and chitosan. $\mathrm{pH}$ adjustments may also influence interactions between carboxylate groups in alginate and chitosan [14].

The viscosity of alginate/HPMC mixtures affected the diameters and densities of beads and the volumes of entrapped drug substance. 
Alginate-chitosan beads increased in diameter with increasing chitosan concentrations, reflecting the formation of polyelectrolyte complexes between carboxyl groups of alginate and amine groups of chitosan [31-34]. Previous studies have shown that bead sizes are normally distributed over 50-2000 $\mu \mathrm{m}$ [35]. The alginate-chitosan beads in the present study had greater average diameters and entrapped more water than alginate/HPMC beads, as indicated by higher moisture contents; however, this led to suboptimal process efficiency due to shrinking during drying phases and manual processing.

Swelling indexes of alginate/HPMC beads increased with increasing concentrations of HPMC, and this likely relates to its hydrophilic properties. In contrast, swelling indexes of alginate-chitosan beads decreased with increasing chitosan concentrations, leading to a stronger structure with increased stability under basic conditions. These structures also became more rigid with increasing chitosan concentrations and with the formation of inter- and intra-polymer linkages on beads [14]. Swelling of beads is caused by differences in osmotic pressure between beads and their surrounding media, as shown in the determination of swelling indexes, in which penetration of solution caused polymer relaxation and swelling of beads [12,25].

Reactions between alginate and chitosan were confirmed by the disappearance of exothermic alginate peaks at $249.08^{\circ} \mathrm{C}$, and exothermic chitosan peaks at $306.96^{\circ} \mathrm{C}$ were replaced with new exothermic peaks at $274.86^{\circ} \mathrm{C}$. Furthermore, an acquired endothermic peak at $205.46^{\circ} \mathrm{C}$ indicated the formation of a linkage between carboxylic ion on alginate and an amine on chitosan. The disappearance of tetrandrine peaks indicated that tetrandrine molecules were dispersed on the beads $[27,36]$. These observations also showed that tetrandrine is entrapped on beads and is chemically altered by heat.

Spectral displacements of alginate carboxylic groups were observed after the formation of complexes with chitosan, with peak shifts from 1608 and $1429 \mathrm{~cm}^{-1}$ to 1616 and $1447 \mathrm{~cm}^{-1}$, respectively (Fig. 5). A new peak was also observed at $2886 \mathrm{~cm}^{-1}$, indicating a $\mathrm{CH}_{2}$ vibration of chitosan [14]. A crosslinking interaction between alginate and calcium ions was evident from a shift of the carboxylic group wavenumber from 1622 to $1634 \mathrm{~cm}^{-1}$ (Fig. 4). No interactions between the drug substance and polymers were evident in these studies, with no significant spectral differences between unloaded and loaded beads.

In a previous study, beads with pores and crevices were associated with diffusion of drugs during gelation [14]. Alginate/HPMC and alginate-chitosan beads were porous and had crevices, although drug release from alginate-chitosan beads was lower than from alginate/ HPMC beads, likely reflecting the density of alginate-chitosan beads and inter- and intra-polymer interactions of alginate, chitosan, and calcium chloride. Swelling indexes were also related to the release of drugs, and beads with lower swelling indexes restrained drugs from the premature release [14].

\section{CONCLUSION}

Beads from the present formulations prematurely released tetrandrine in $\mathrm{HCl}$ at $\mathrm{pH}$ 1.2. Therefore, calcium alginate-chitosan and alginate/ HPMC beads containing tetrandrine may fail as colon-targeted dosage forms.

\section{CONFLICTS OF INTEREST}

All authors have none to declare.

\section{REFERENCES}

1. Kosaraju SL. Colon targeted delivery systems: Review of polysaccharides for encapsulation and delivery. Crit Rev Food Sci Nutr 2005;45:251-8.

2. Amidon S, Brown JE, Dave VS. Colon-targeted oral drug delivery systems: Design trends and approaches. AAPS PharmSciTech
2015;16:731-41.

3. Wilson CG, Crowley PJ. Controlled Release in Oral Drug Delivery. New York: Springer; 2011.

4. Pinto JF. Site-specific drug delivery systems within the gastro-intestinal tract: From the mouth to the colon. Int J Pharm 2010;395:44-52.

5. Wang QS, Wang GF, Zhou J, Gao LN, Cui YL. Colon targeted oral drug delivery system based on alginate-chitosan microspheres loaded with icariin in the treatment of ulcerative colitis. Int J Pharm 2016;515:176-85.

6. Nussinovitch A. Polymer Macro-and Micro-Gel Beads: Fundamentals and Applications. New York: Springer Science Business Media; 2010.

7. Rieder F, Fiocchi C. Intestinal fibrosis in inflammatory bowel disease-current knowledge and future perspectives. J Crohns Colitis 2008;2:279-90.

8. Iswandana R, Pham BT, van Haaften WT, Luangmonkong T, Oosterhuis $\mathrm{D}$, Mutsaers HA, et al. Organ-and species-specifc biological activity of rosmarinic acid. Toxicol In Vitro 2016;32:261-8.

9. Rieder F, Bettenworth D, Imai J, Inagaki Y. Intestinal fibrosis and liver fibrosis: Consequences of chronic inflammation or independent pathophysiology? Inflamm Intest Dis 2016;1:41-9.

10. Jin H, Li L, Zhong D, Liu J, Chen X, Zheng J, et al. Pulmonary toxicity and metabolic activation of tetrandrine in CD-1 mice. Chem Res Toxicol 2011;24:2142-52.

11. Goh C, Heng P, Chan L. Alginates as a useful natural polymer for microencapsulation and therapeutic applications. Carbohydr Polym 2012;88:1-12

12. Iswandana R, Putri KS, Wulandari FR, Najuda G, Sari SP, Djajadisastra J. Preparation of calcium alginate-tetrandrine beads using ionic gelation method as colon-targeted dosage form. J Appl Pharm Sci 2018;8:68-74.

13. Patel N, Lalwani D, Gollmer S, Injeti E, Sari Y, Nesamony J, et al. Development and evaluation of a calcium alginate based oral ceftriaxone sodium formulation. Prog Biomater 2016;5:117-33.

14. Tahtat D, Mahlous M, Benamer S, Khodja AN, Oussedik-Oumehdi H, Laraba-Djebari F, et al. Oral delivery of insulin from alginate/chitosan crosslinked by glutaraldehyde. Int J Biol Macromol 2013;58:160-8.

15. Timmins P, Pygall SR, Melia CD. AAPS advances in the pharmaceutical sciences series. In: Hydrophilic Matrix Tablets for Oral Controlled Release. New York: Springer; 2014.

16. Abdalla KF, Kamoun EA, El Maghraby GM. Optimization of the entrapment efficiency and release of ambroxol hydrochloride alginate beads. J Appl Pharm Sci 2015:5:13-9.

17. Iswandana R, Putri KS, Dwiputra R, Yanuari T, Sari SP, Djajadisastra J. Formulation of chitosan tripolyphosphate-tetrandrine beads using ionic gelation method: In vitro and in vivo evaluation. Int J App Pharm 2017;9:109-15.

18. Pandey S, Mishra A, Raval P, Patel H, Gupta A, Shah D, et al. Chitosanpectin polyelectrolyte complex as a carrier for colon targeted drug delivery. J Young Pharm 2013;5:160-6.

19. Iswandana R, Putri KS, Sandiata CE, Triani S, Sari SP, Djajadisastra J. Formulation of tetrandrine beads using ionic gelation method capectinate coated $\mathrm{PH}$-sensitive polymers as colon-targeted dosage form. Asian J Pharm Clin Res 2017;10:90-5.

20. Raval MK, Prajapati DU, Varma SM, Khodifad MA, Patel JM, Sheth NR. Influence of some hydrophilic polymers on dissolution characteristics of furosemide through solid dispersion: An unsatisfied attempt for immediate release formulation. J Pharm Negat Results 2010;1:29-34

21. Siepmann J, Peppas N. Modeling of drug release from delivery systems based on hydroxypropyl methylcellulose (HPMC). Adv Drug Deliv Rev 2012;64:163-74.

22. Takka S, Gürel A. Evaluation of chitosan/alginate beads using experimental design: Formulation and in vitro characterization. AAPS PharmSciTech 2010;11:460-6.

23. Verma A, Sharma M, Verma N, Pandit JK. Floating alginate beads: Studies on formulation factors for improved drug entrapment efficiency and in vitro release. Farmacia 2013;61:143-61.

24. Rajendran A, Basu SK. Alginate-chitosan particulate system for sustained release of nimodipine. Trop J Pharm Res 2009;5:433-40.

25. Hua S, Marks E, Schneider JJ, Keely S. Advances in oral nano-delivery systems for colon targeted drug delivery in inflammatory bowel disease: Selective targeting to diseased versus healthy tissue. Nanomedicine 2015;11:1117-32.

26. Damian F, Blaton N, Naesens L, Balzarini J, Kinget R, Augustijns $\mathrm{P}$, et al. Physicochemical characterization of solid dispersions of the antiviral agent UC-781 with polyethylene glycol 6000 and gelucire 44/14. Eur J Pharm Sci 2000;10:311-22. 
27. Sankalia MG, Mashru RC, Sankalia JM, Sutariya VB. Reversed chitosan-alginate polyelectrolyte complex for stability improvement of alpha-amylase: Optimization and physicochemical characterization. Eur J Pharm Biopharm 2007;65:215-32.

28. Jiang XH, Yang JQ, Li N, Wang H, Zhou QX. The pharmacokinetical study of plant alkaloid tetrandrine with a simple HPLC method in rabbits. Fitoterapia 2011;82:878-82.

29. Yang L, Chu JS, Fix JA. Colon-specific drug delivery: New approaches and in vitro/in vivo evaluation. Int J Pharm 2002;235:1-5.

30. Voo W, Ooi C, Islam A, Tey B, Chan E. Calcium alginate hydrogel beads with high stiffness and extended dissolution behaviour. Eur Poly J 2016;75:343-53

31. Mujtaba A, Ali M, Kohli K. Formulation of extended release cefpodoxime proxetil chitosan-alginate beads using quality by design approach. Int J Biol Macromol 2014;69:420-9.

32. Shaji J, Shaikh M. Formulation, optimization, and characterization of biocompatible inhalable D-cycloserine-loaded alginate-chitosan nanoparticles for pulmonary drug delivery. Asian J Pharm Clin Res 2016;9:82-95

33. Lavanya N, Muzib I, Jithan A, Umamahesh B. Novel nanoparticles for the oral delivery og low molecular weight heparin: In vitro and in vivo assessment. Asian J Pharm Clin Res 2017;10:254-61.

34. Nair SC, Kumar BS, Krishna R, Lakshmi PS, Vasudev DT. Formulation and evaluation of niosomal suspension of cefixime. Asian J Pharm Clin Res 2017;10:194-201.

35. Atyabi F, Majzoob S, Iman M, Salehi M, Dorkoosh F. In vitro evaluation and modification of pectinate gel beads containing trimethyl chitosan, as a multi-particulate system for delivery of water-soluble macromolecules to colon. Carbohydr Polym 2005;61:39-51.

36. Liu Z, Li J, Nie S, Liu H, Ding P, Pan W, et al. Study of an alginate/ HPMC-based in situ gelling ophthalmic delivery system for gatifloxacin. Int J Pharm 2006;315:12-7. 